\section{DERECHOS Y DEBERES DE LOS CIUDADANOS: DE LOS USUARIOS Y DE LOS TRABAJADORES DE SALUD}

\section{RIGHTS AND DUTIES OF CITIZENS: HEALTH USERS AND HEALTH WORKERS}

\author{
Pedro Jesús Mendoza-Arana ${ }^{1,2, a}$
}

Señor Editor. Hemos revisado con atención el artículo de Gil-Quevedo et al. acerca de los ciudadanos informados y empoderados como elementos clave para el ejercicio de los derechos en salud ${ }^{(1)}$. Si bien compartimos el concepto fundamental que subyace a este planteamiento que, entendemos, es el principio de autonomía de la persona y su derecho a la salud y a la atención de salud, nos preocupa que no haya una definición clara del significado de ciudadano "empoderado", y que, en todo el artículo no se mencione el concepto de deberes del ciudadano en materia de salud y atención de salud.

El concepto de empoderamiento surge en las ciencias sociales como una propuesta que busca que determinados grupos sociales, percibidos en una situación de desventaja frente a otros, se sitúen en un nivel de igualdad. Dada la raíz del término, la desventaja se refiere a relaciones de poder en la sociedad, y en esta lógica, se ha empleado extensamente en el análisis de desigualdades de género, étnicas, y formas diversas de discriminación.

Sin embargo, así como el ciudadano es un actor clave en los servicios de salud visto como usuario, lo es también el personal de salud, que son también ciudadanos, y que, en años recientes, se empieza a hacer visible que están expuestos, tanto a riesgos ocupacionales derivados de la bioseguridad y el estrés, como a ser objeto de violencia por parte de los familiares de los pacientes, en un ejercicio mal entendido de su creciente empoderamiento.

En el estudio de Travetto C. et al. (2), realizado en personal de salud en América Latina, se identificó que un $67 \%$ había sufrido algún tipo de agresión en el último año, siendo este porcentaje mayor en enfermeros y médicos, llegando, incluso, a un $71 \%$. De acuerdo con la misma encuesta, los principales desencadenantes habrían sido la demora en la atención y la

\footnotetext{
Universidad Nacional Mayor de San Marcos. Lima, Perú

Academia Nacional de Medicina. Lima, Perú

Médico cirujano, doctor en Medicina

Recibido: 24/09/2017 Aprobado: 25/10/2017 En línea: 15/11/2017
}

Citar como: Mendoza-Arana PJ. Derechos y deberes de los ciudadanos: de los usuarios y de los trabajadores de salud. Rev Peru Med Exp Salud Publica. 2017;34(4):754. doi: 10.17843/rpmesp.2017.344.3132. carencia de recursos para resolver problemas médicos. En ese mismo sentido, en Perú, en el año 2014 (3), un 20\% de médicos reportaron violencia tipo amenaza y en el $2016^{(4)}$, un $47 \%$ de médicos reportaron haber sufrido violencia, siendo el agresor, en el $43 \%$ de los casos, el familiar, y en $26 \%$ un acompañante del paciente.

Sin restar importancia a la necesidad de difundir y defender los derechos del paciente a una atención oportuna y de calidad, consideramos que esta defensa debe, en simultáneo, implicar la promoción del derecho del personal de salud a ser respetados como seres humanos, ciudadanos y trabajadores. Para los investigadores, implica un llamado para entender esta dinámica entre profesionales de la salud y los pacientes, que muchos perciben en evolución ${ }^{(5)}$; para los docentes, conlleva una invocación a formar nuevos profesionales en una cultura de promoción a los derechos y deberes de los usuarios y del personal de salud, todos ciudadanos en salud.

Contribución de los autores: PJMA declara ser el único autor del artículo.

Fuentes de financiamiento: autofinanciado.

Conflictos de interés: el autor manifiesta no tener conflictos de interés.

\section{REFERENCIAS BIBLIOGRÁFICAS}

1. Gil-Quevedo W, Agurto-Távara E, Espinoza-Portilla E. Ciudadanos informados y empoderados: claves para el pleno ejercicio de los derechos en salud. Rev Peru Med Exp Salud Publica. 2017;34(2):311-5. doi: 10.17843/ rpmesp.2017.342.2747.

2. Travetto C, Daciuk N, Fernández S, Ortiz P, Mastandueno R, Prats M, et al. Agresiones hacia profesionales en el ámbito de la salud. Rev Panam Salud Publica. 2015;38(4):307-15.

3. Tuya-Figueroa X, Mezones-Holguin E, Monge E, Arones R, Mier M, Saravia M, Torres J, Mayta-Tristán P. Violencia laboral externa tipo amenaza contra médicos en servicios hospitalarios de Lima Metropolitana, Perú 2014. Rev Peru Med Exp Salud Publica. 2016;33(4):670-79. doi: 10.17843/ rpmesp.2016.334.2550.

4. Muñoz del Carpio Toia A, Valdivia Fernández B, Velasquez Lazo C, Valdivia Rodríguez M, Arroyo Tovar GY, Toia Larsen M, et al. Violencia contra médicos en hospitales de Arequipa, Perú 2016. Acta Med Peru. 2016;33(2):99-104.

5. Tucker JD, Cheng Y, Wong B, Gong N, Nie JB, Zhu W, et al. Patient-physician mistrust and violence against physicians in Guangdong Province, China: A qualitative study. BMJ Open. 2015;5(10):e008221. doi: 10.1136/bmjopen-2015-008221.

Correspondencia: Pedro Jesús Mendoza-Arana

Dirección: Av. Grau 700, Lima 1, Perú

Teléfono: $(+511) 980442538$

Correo electrónico:pedro.mendoza.arana@gmail.com. 